\title{
Newer advances, newer challenges?
}

\author{
Demetrios N. Mallios, MD, and S. Ram Kumar, MD, PhD, FACS
}

\footnotetext{
From the Division of Cardiac Surgery, Department of Surgery, Keck School of Medicine of the University of Southern California, Heart Institute, Children's Hospital Los Angeles, Los Angeles, Calif.

This work was supported in part by National Heart, Lung, and Blood Institute Grant K08HL121191 to S.R.K. and Heart and Lung Surgery Foundation Grant to D.N.M.

Disclosures: Authors have nothing to disclose with regard to commercial support.

Received for publication Aug 29, 2018; accepted for publication Aug 29, 2018; available ahead of print Oct 5, 2018.

Address for reprints: S. Ram Kumar, MD, PhD, FACS, Children's Hospital, Los Angeles, 4650 Sunset Blvd, Mailstop \#66, Los Angeles, CA 90027 (E-mail: rsubramanyan@chla.usc.edu).

J Thorac Cardiovasc Surg 2019;157:e9-10

$0022-5223 / \$ 36.00$

Copyright (C) 2018 by The American Association for Thoracic Surgery

https://doi.org/10.1016/j.jtcvs.2018.08.074
}

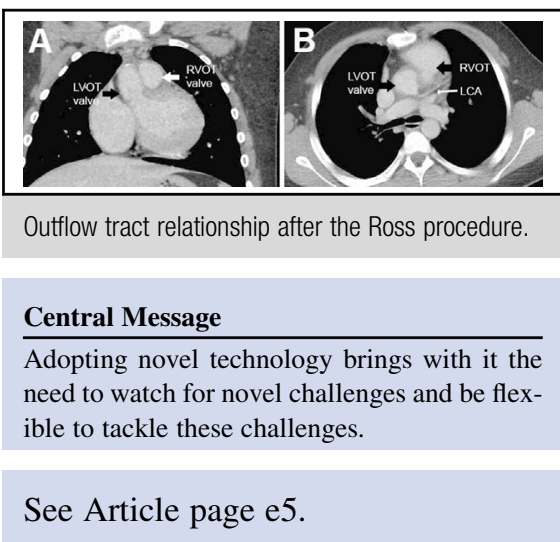

The ability to percutaneously implant cardiac valves represents a major step forward in the care of patients with heart disease. Transcatheter aortic valves were initially implanted in adults with prohibitive risk for surgical valve replacement. In children, transcatheter pulmonary valve replacement (TPVR) has been shown to be a low-risk procedure with high technical success rates and a favorable outcome profile in the intermediate term. ${ }^{1}$ The Melody (Medtronic, Minneapolis, Minn) valve system composed of a bovine jugular venous valve within a platinum-iridium stent frame is the most widely used transcatheter pulmonary valve. Although currently approved by the Food and Drug Administration for use in a dysfunctional conduit or bioprosthetic valve only, it is being increasingly used off label in native right ventricular outflow tracts (RVOTs) and after transannular patch augmentation of RVOT. Despite the advantages to TPVR, Melody valves have a significantly higher incidence of endocarditis compared with surgical valves, ${ }^{1,2}$ and the incidence of infection seems to increase with duration of follow-up.

We and others have shown that the Ross procedure is a safe, effective, and Coumadin-free (Bristol-Myers Squib, New York, NY) alternative to aortic valve replacement across all age groups (Figure 1). ${ }^{3,4}$ The need for reintervention after a Ross procedure appears to vary with age. Reintervention in the autograft root in the left ventricular outflow due to root dilation is more common in older patients and can often be addressed using valvesparing approaches. ${ }^{5}$ In these older patients, it appears that the orthotopic position of the reconstructed RVOT leads to better longevity. However, especially when the Ross procedure is undertaken in small children, the RVOT valve is unable to keep up with somatic growth and requires replacement over time. TPVR serves to extend the life of the RVOT conduit. ${ }^{6}$ That said, there seems to be some unique challenges to TPVR in the Ross population. Although the relatively "usual" position of the coronary arteries with respect to the orthotopically placed conduit should favor TPVR placement, coronary compression precludes TPVR in approximately $10 \%$ of patients who underwent the Ross. In the setting of dilation of the neoaortic root, a stented Melody valve can have significant mass effect predisposing to neoaortic valve insufficiency by distortion of root geometry or aortopulmonary fistula. ${ }^{7,8}$

The infectious risk associated with a Melody valve has special consequences in the Ross patient. We and others have shown that encasement of the autograft root in a Dacron tube can decrease root dilation and need for reintervention. $^{3,9}$ It is common practice to prestent the RVOT conduit before TPVR or place TPVR within a failed bioprosthetic valve in the RVOT. All of these modifications increase the prosthetic material burden and can render clearing of infections particularly problematic. In this issue of the Journal, Kumar and colleagues ${ }^{10}$ present an interesting case report of a patient with life-threatening prosthetic aortic valve endocarditis due to spread of infection from a Melody valve in the RVOT. Clearly, in this patient, the presence of a prosthetic valve in the aortic position (regardless of his prior Ross procedure) predisposed him to spread of endocarditis. The authors do well to explain the nuances and challenges of surgical management in this setting. They need to be commended for a successful surgical strategy using a homograft in each outflow tract resulting in effective infection control and patient survival. One can easily comprehend how this situation can result in a less desirable outcome.

So, what do we learn from the authors' experience? Although primary antibiotic therapy is often attempted for 

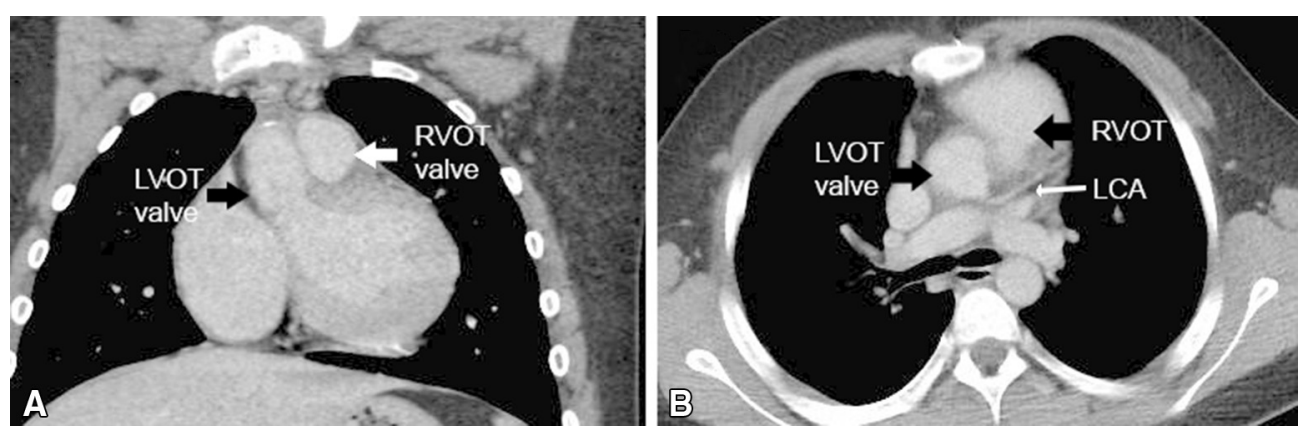

FIGURE 1. Coronal (A) and transverse (B) cuts from a computed tomography scan in a patient after the Ross procedure showing the anatomic, yet close, proximity of the autograft in the left ventricular outflow tract and, in this case, homograft in the RVOT. Also seen is the left coronary running posterior and adjacent to the reconstructed RVOT. LVOT, Left ventricular outflow tract; RVOT, right ventricular outflow tract; LCA, left coronary artery.

suspected endocarditis after TPVR with some success, there are situations when early, aggressive surgical intervention may be warranted. As in this patient, or in other circumstances where the prosthetic burden is high, medical management alone is unlikely to result in infection control. Surgical intervention after TPVR, especially with multiple stents in the RVOT, can be particularly challenging. As TPVR becomes more prevalent and patients survive to require subsequent surgical RVOT interventions, cardiac surgeons need to be better prepared to approach these tricky procedures. As technology advances offering us novel solutions, we also inherit novel challenges for the future. Embracing new technology requires the discipline to continue to learn the challenges that come with it and be flexible to adopt newer approaches to tackle these challenges.

\section{References}

1. Chatterjee A, Bajaj N, McMahon WS, Cribbs MG, White JS, Mukherjee A, et al Transcatheter pulmonary valve implantation: a comprehensive systematic review and meta-analyses of observational studies. J Am Heart Assoc. 2017;6:e006432.
2. O’Donnell C, Holloway R, Tilton E, Stirling J, Finucane K, Wilson N. Infective endocarditis following Melody valve implantation: comparison with a surgical cohort. Cardiol Young. 2017;27:294-301.

3. Bansal N, Kumar SR, Baker CJ, Lemus R, Wells WJ, Starnes VA, et al. Agerelated outcomes of the Ross procedure over 20 years. Ann Thorac Surg. 2015; 99:2077-83.

4. Nelson JS, Pasquali SK, Pratt CN, Yu S, Donohue JE, Loccoh E, et al. Long-term survival and reintervention after the ross procedure across the pediatric age spectrum. Ann Thorac Surg. 2015;99:2086-95.

5. Kumar SR, Bansal N, Wells WJ, Starnes VA. Outcomes of reintervention on the autograft after Ross procedure. Ann Thorac Surg. 2016;102:1517-21.

6. Gillespie MJ, McElhinney DB, Kreutzer J, Hellenbrand WE, El-Said H, Ewert P, et al. Transcatheter pulmonary valve replacement for right ventricular outflow tract conduit dysfunction after the Ross procedure. Ann Thorac Surg. 2015; 100:996-1002.

7. Friedman KG, McElhinney DB, Rhodes J, Powell AJ, Colan SD, Lock JE, et al. Left ventricular diastolic function in children and young adults with congenital aortic valve disease. Am J Cardiol. 2013;111:243-9.

8. Kenny D, Holoshitz N, Turner D, Hijazi Z. Aortopulmonary fistula after transcatheter pulmonary valve replacement. Circ Cardiovasc Interv. 2013;6: e67-8.

9. Ungerleider RM, Ootaki Y, Shen I, Welke KF. Modified Ross procedure to prevent autograft dilatation. Ann Thorac Surg. 2010;90:1035-7.

10. Kumar TKS, Balduf K, Boston U, Knott-Craig C. Biventricular root replacement for transcatheter pulmonary valve endocarditis after Ross operation: double the trouble. J Thorac Cardiovasc Surg. 2019;157:e5-7. 